\title{
DETECCIÓN DE LA TOXINA TERMOLÁBIL DE Escherichia coli EN QUESOS FRESCOS ARTESANALES MEDIANTE PCR
}

\author{
Detection of the termolábil toxin of Escherichia coli in fresh cheeses artesanales \\ by means of PCR
}

\author{
Dániza M. Guerrero A. ${ }^{1}$ y Gladys C. Arias A. ${ }^{2}$ \\ Facultad de Ingeniería Pesquera y de Alimentos, $\mathrm{UNAC}^{3}$ \\ Facultad de Farmacia y Bioquímica, Universidad Nacional Mayor de San Marcos ${ }^{2}$
}

\begin{abstract}
RESUMEN
En la presente investigación se detectó presencia de toxina termolábil de Escherichia coli, mediante la técnica de la reacción en cadena de la polimerasa (PCR), en 24 muestras de quesos frescos manufacturados con leche de cabra y vaca. Se optó por el método de PCR por las ventajas que ofrece respecto a otros métodos de análisis, en cuanto a confiabilidad y rapidez de obtención de los resultados.

De 24 muestras de queso (cabra y vaca) analizadas, el 58,33\% fueron positivas; $72,72 \%$ de las muestras de queso fresco de cabra y $46,16 \%$ de las muestras de quesos de leche de vaca. Por otra parte, el análisis de $X^{2}$ demostró, con $99 \%$ de confiabilidad, que los resultados positivos y negativos de las muestras analizadas no dependen del tipo de queso sino de otros factores, como las buenas prácticas de manufactura y la estandarización del procedimiento.
\end{abstract}

Palabras clave: Escherichia coli, toxina termolábil, queso fresco de cabra y vaca.

\section{SUMMARY}

This research was conducted using the Polymerase Chain Reaction (PCR) to detect heat-labile toxin of Escherichia coli in 24 fresh cheeses manufactured with cow and goat milk. The advantages of the PCR technique, over other analysis techniques, are reliability and rapidity to obtain the results.

2.4 samples of cheese (from cow and goat milk) were studied obtaining $58.33 \%$ of positive cases; $72.72 \%$ were positive with fresh goat milk and $46.16 \%$ of cow milk. Moreover, the X2 analysis showed, with $99 \%$ reliability, that the positive and negative results of the samples tested did not depend on the type of cheese used but did so on other factors, such as good manufacturing practices and standardization of the procedure.

Keywords: Escherichia coli, heat - labile toxin, fresh cheeses cow and goat milk.

\section{INTRODUCCION}

La industria lechera nacional produce quesos empleando leche de vaca. En la transformación de la leche en queso, se aplica un conjunto de operaciones que implican medidas de control de parámetros y buenas prácticas de manufactura. Los pequeños productores de quesos, en cambio, no toman en cuenta las condiciones sanitarias ni medioambientales necesarias; emplean leche cruda, que procede generalmente de la mezcla de ordeños de días anteriores, y el trabajo se hace en forma manual. Sus equipos consisten, en la mayoría de casos, en latas, baldes plásticos u ollas, que son ubicadas al medio ambiente y expuestos al aire, al polvo, a los insectos, al movimiento de los animales, etc. Los quesos frescos procesados de esta manera tienen una amplia y diversa carga microbiana que constituyen un peligro para la salud pública (1).

Escherichia coli(2) es una bacteria que se encuentra normalmente en el intestino de los animales saludables, incluido el humano y, por ende, en las aguas servidas. La mayoría son inocuas. Fue descrita por primera vez por Theodor von 
Escherich en 1885, quién la denominó Bacterium coli. La cepa responsable de patología se ha venido describiendo desde la década de los años 40 como Escherichía coli enteropatógena clásica; con posterioridad se ha añadido a este grupo otras cepas igualmente patógenas que causan enteritis por un mecanismo invasor rigurosamente idéntico al de las Shiguellas, el microorganismo responsable de la disentería bacilar. Actualmente en el listado de bacterias asociadas a la producción de diarrea aguda $(2,3)$ en la infancia se considera a $E$. coli enteropatógena clásica, $E$. coli enterotoxigénica, $E$. coli enteroagregativa, E. coli difusa adherente, E. coli enteroinvasora, y E. coli enterohemorrágica.

Escherichia coli entero toxigénica causa diarrea no sanguinolenta en niños y adultos, sobre todo en países en vías de desarrollo y personas en tránsito. Produce dos enterotoxinas denominadas toxinas citotóxicas: una termolábil (LT) semejante en estructura y en mecanismo de acción a la toxina del cólera, y otra termoestable (ST) que no produce cambios estructurales sino funcionales (aumento en la pérdida neta de agua y electrolitos) en el intestino delgado.

Los factores responsables de la diarrea son, en primer lugar los factores de colonización que facilitan la unión de la bacteria a la mucosa epitelial del intestino delgado y en segundo lugar sus enterotoxinas, tanto estable como lábil; estas cepas pueden expresar sólo la toxina lábil o la termoestable, ó ambas.

Otro riesgo no menos importante es la demora en detectar la presencia activa de microorganismos que producen toxinas mediante el empleo de procedimientos convencionales. Por ello es necesario contar con metodologías sensibles y rápidas en la detección de Escherichia coli enterotoxigénica, especialmente productora de toxina termolábil, determinar eficientemente todos los casos positivos y evitar errores que se suelen cometer con los medios de cultivo y sistemas rápidos que detectan falsos positivos; es decir especies de Escherichia coli no patógena como si lo fueran.

Existen varios métodos para caracterizar las toxinas de esta cepa de Escherichia coli, mediante ensayos biológicos con conejos y ratones lactantes. El ensayo tradicional (4) involucra el uso de cultivos celulares (células adrenales y/o células CHO -Chinese hamster ovary); los ensayos inmunológicos, disponibles y de uso en los laboratorios clínicos son ELISA, aglutinación de partículas de látex, aglutinación reversa y pasiva y coaglutinación.

Con la disponibilidad del método de prueba de un gen (5), los alimentos pueden ser analizados directamente para determinar la presencia de Escherichia coli enterotoxigénica y el análisis es completado en aproximadamente tres días. Los métodos alternativos que incluyen enriquecimiento y cultivo de la muestra para su subsiguiente confirmación como raza toxigénica, mediante pruebas convencionales con la toxina, pueden tomar al menos siete días.

Nuevos ensayos (6) que identifiquen más rápidamente las razas peligrosas de $E$. coli han sido desarrollados por científicos del servicio de investigación agrícola de Wyndmoor, Pensylvania, ya que el procedimiento de serotipificación que permite diferenciar los tipos peligrosos de $E$. coli de otros que no lo son, requieren de mucho tiempo y trabajo y; porque se ha evidenciado recientemente que esta bacteria está asociada a problemas de mastitis (7) en vacas.

Por tanto, el objetivo del presente estudio fue detectar la toxina termolábil de Escherichia coli enterotoxigénica, en quesos frescos artesanales obtenidos con leche cruda de cabra y de vaca, mediante la reacción en cadena de la polimerasa(PCR).

\section{MATERIALES Y MÉTODOS}

El presente trabajo de investigación se realizó en los laboratorios de la Universidad Nacional del Callao, y en el laboratorio de investigación molecular MAM-lab.

\section{Material biológico}

Veinticuatro (24) muestras de queso artesanal fueron adquiridas en el mercado de abastos del Callao. Once (11) muestras de queso de leche de cabra y trece (13) muestras de queso de vaca.

\section{Secuencia génica de Escherichia coli enterotoxigénica}

La procedencia génica fue la correspondiente al Gen heat labile enterotoxin, Genbank key: JO1646.

\section{Obtención de las muestras}

Las muestras de quesos se transportaron guardándolas previamente codificadas en bolsas 
estériles, con cierre y en un cooler. Se registraron las características externas de cada una de las 24 muestras. Se extrajeron aproximadamente 10 gramos de cada una de las muestra en condiciones estrictas de bioseguridad.

\section{Extracción y Purificación del ADN}

En el laboratorio de Investigación Molecular MAM-lab (8), el material biológico fue sometido a digestión enzimática, purificación del ADN con solventes orgánicos y cuantificación espectrofotométrica del ácido nucleico.

\section{Reacción en cadena de la polimerasa (PCR)}

La mezcla de reacción para el primer evento se preparó considerando un volumen total de $50 \mu 1$, con 100 pmol de cada cebador sentido1/ antisentido 1 correspondiente al segmento del gen del antígeno de ADN de Escherichia coli productora de toxina termolábil de $301 \mathrm{pb} ; 2,5 \mathrm{U}$ de Taq gold DNA-AB y $5 \mu$ l del ADN en estudio.

La mezcla se sometió a un primer evento de 30 ciclos de amplificación, constituido por: desnaturalización del $\mathrm{ADN}$ a $94^{\circ} \mathrm{C}$ durante un minuto, hibridación de los cebadores a $58^{\circ} \mathrm{C}$ por un minuto, y extensión de los cebadores a $72^{\circ} \mathrm{C}$ por un minuto en un Termociclador AB2400.

Se emplearon controles de amplificación positivo,

negativo y blanco de referencia.

\title{
Análisis electroforético
}

Los amplicones post PCR fueron visualizados en geles de agarosa al $4 \%$, coloreados con bromuro de etidio.

\section{Análisis estadístico}

Los resultados fueron analizados mediante la prueba de $\mathrm{X} 2$, con un nivel de confianza del $99 \%$.

\begin{abstract}
RESULTADOS
En las muestras de quesos de leche de cabra $(n=11)$ se observaron las siguientes características internas y externas: manchas marrones superficiales y residuos de madera ya que algunos de los quesos habían sido ahumados, presentando consistencia compacta. Las muestras no ahumadas eran poco consistentes y exudaban suero, el color de la cuajada fue grisáceo, notándose además pelos y piedritas en todas las muestras. Estos quesos tuvieron la particularidad de que los vendedores las cubrían con hojas de plátano para su expendio. Los resultados de la reacción en cadena de la polimerasa se citan en las tablas 2 y 3 .
\end{abstract}

Tabla 1.

Resultados de PCR obtenidos en los quesos frescos de leche de cabra

\begin{tabular}{|c|c|c|}
\hline Código de la Muestra & $\begin{array}{c}\text { Resultado } \\
\text { de PCR }\end{array}$ & $\begin{array}{c}\text { Observación } \\
\text { (ADN obtenido) }\end{array}$ \\
\hline 17901 & negativo & Poco ADN \\
\hline 17902 & positivo & Cantidad adecuada \\
\hline 17903 & negativo & Poco ADN \\
\hline 17904 & positivo & Cantidad adecuada \\
\hline 17905 & positivo & Cantidad adecuada \\
\hline 17906 & positivo & Cantidad adecuada \\
\hline 17907 & positivo & Cantidad adecuada \\
\hline 17908 & positivo & Cantidad adecuada \\
\hline 17909 & positivo & Cantidad adecuada \\
\hline 17910 & positivo & Cantidad adecuada \\
\hline 17911 & negativo & Poco ADN \\
\hline & & \\
\hline
\end{tabular}


En los quesos de leche de vaca $(n=13)$ se observó las siguientes características externas e internas: quesos de textura predominantemente compacta y color crema, con presencia de partículas extrañas consistentes en piedritas y pelos.
Las muestras de requesón fueron de color gris, con abundantes partículas de tierra y piedritas, y exudaban suero lechoso. Los resultados de la reacción en cadena de la polimerasa se exponen a continuación.

Tabla 2.

Resultados de PCR obtenidos en los quesos frescos de leche de vaca

\begin{tabular}{|c|c|c|}
\hline $\begin{array}{c}\text { Código de la } \\
\text { Muestra }\end{array}$ & $\begin{array}{c}\text { Resultado } \\
\text { de PCR }\end{array}$ & $\begin{array}{c}\text { Observación } \\
\text { (ADN obtenido) }\end{array}$ \\
\hline 17912 & negativo & Poco ADN \\
\hline 17913 & negativo & Cantidad adecuada \\
\hline 17914 & positivo & Cantidad adecuada \\
\hline 17915 & negativo & Poco ADN \\
\hline 17916 & positivo & Cantidad adecuada \\
\hline 17917 & positivo & Cantidad adecuada \\
\hline 17918 & negativo & Cantidad adecuada \\
\hline 17919 & negativo & Cantidad adecuada \\
\hline 17920 & negativo & Poco ADN \\
\hline 17921 & negativo & Cantidad adecuada \\
\hline 17922 & positivo & Cantidad adecuada \\
\hline 17923 & positivo & Cantidad adecuada \\
\hline 17924 & positivo & Cantidad adecuada \\
\hline
\end{tabular}

Los resultados positivos en quesos de leche de cabra fueron 8 de 11 muestras, equivalente al $72,72 \%$, mientras que las muestras con resultados negativos fueron 3 , equivalente al $27.28 \%$.

De igual manera, los resultados positivos en quesos procesados con leche de vaca fueron 6 de un total de 13 muestras, es decir un porcentaje de $46,16 \% . y$, los resultados negativos fueron 7 que equivale al $53,84 \%$.

Considerando el total de muestras de quesos artesanales, el porcentaje de quesos artesanales que poseían la toxina termolábil de Escherichin coli fue de $58.33 \%$ y $41.67 \%$ el porcentaje de muestras exentas de la toxina termolábil.

\section{Análisis electroforético de los amplicones}

En la figura 1, se presenta el corrido electroforético de amplicones procedentes tanto de quesos procesados con leche de cabra como de vaca, con un marker correspondiente a la toxina termolábil de Escherichia coli, de 301 pares de bases.
En el gel de agarosa se puede observar los resultados positivos y negativos, así como la presencia del control positivo de referencia.

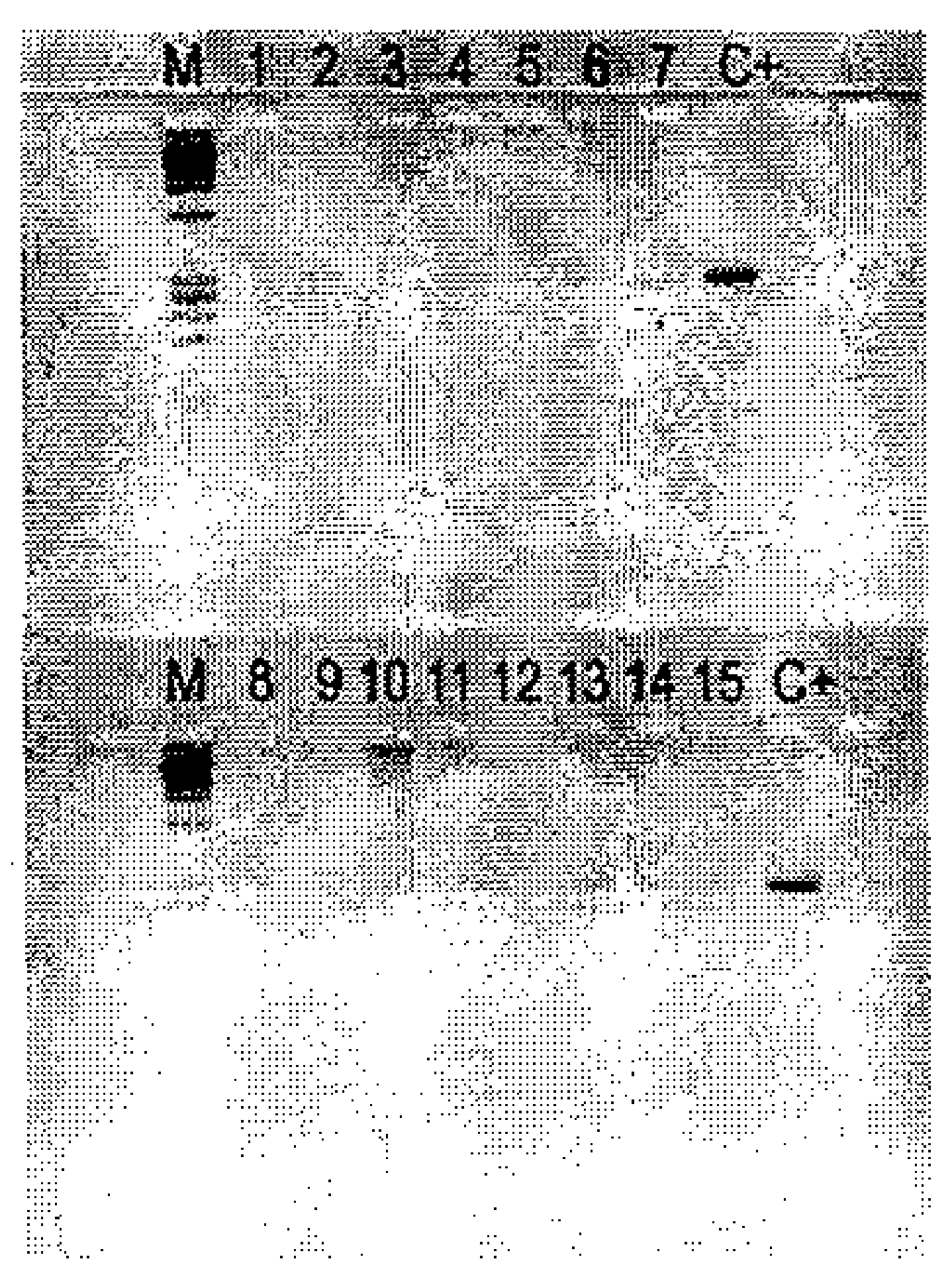

Figura 1. Electroforesis de los amplicones de muestras de queso de cabra y vaca. 


\section{Análisis estadístico}

Debido a la alta sensibilidad de la metodología de la reacción en cadena de la polimerasa (PCR), el análisis estadístico $(8,9)$ se hizo entre las fre- cuencias observadas y esperadas de las 24 muestras de queso en base al estadístico de $\mathrm{X} 2$, con los siguientes resultados.

\begin{tabular}{|c|c|c|c|}
\hline $\begin{array}{c}\text { Toxina termolábil de } \\
\text { Escherichia coli } \\
\text { enterotoxigénica }\end{array}$ & $\begin{array}{c}\text { Queso de } \\
\text { leche } \\
\text { de cabra }\end{array}$ & $\begin{array}{c}\text { Queso } \\
\text { de leche } \\
\text { de vaca }\end{array}$ & TOTAL \\
\hline Positivo & $8(6.41)$ & $6(8.16)$ & 14 \\
\hline Negativo & $3(4.58)$ & $7(5.83)$ & 10 \\
\hline Total & 11 & 13 & 24 \\
\hline
\end{tabular}

$\mathrm{Al}$ admitirse la independencia de los factores (resultados positivos y negativos de la presencia de E coli productora de toxina termolábil), la probabilidad de los niveles cruzados fue estimado como el producto de los estimadores de las probabilidades de cada uno de ellos.

Se calcularon las frecuencias esperadas, así como la desviación de las frecuencias observadas y esperadas, siendo 1,73. Para un valor de $a=0.01$, la región de rechazo que le corresponde a la prueba según la distribución X2 con (2-1) (2-1) grados de libertad fue igual a 6.63 .

Luego, con un nivel de significación del 1\% se pudo concluir que no fue posible asegurar que el tipo de queso fresco (procesado con leche de cabra o con leche de vaca), influya en el resultado positivo o negativo de la detección de la toxina termolábil de Escherichia coli mediante la PCR.

\section{DISCUSION}

Para que un alimento sea considerado de buena calidad (10) debe cumplir los siguientes requisitos: ser nutritivo (el aporte de nutrientes varía según el producto), idóneo (su naturaleza y composición deben corresponder a aquellas que le son propias), fresco (carente de deterioro), sensorialmente aceptable, e inocuo (que no cause daño).

Desde hace varias décadas, la industria lechera ha contado con la pasteurización como el método más eficaz para eliminar patógenos en la leche, influyendo así en la baja frecuencia con la cual los productos lácteos participan como vehículos en brotes de enfermedades transmitidas por alimentos (ETAs); pero no es el caso de los lácteos artesanales procesados con leche cruda o no pasteurizada. Olsen (11), asegura que el consumo de productos lácteos procesados con leche no pasteurizada es uno de los factores más relevantes en la adquisición de enfermedades ligadas al consumo de estos alimentos; tal como se observó en el presente estudio. Actualmente se da mucha importancia a la inocuidad de los alimentos porque impacta tanto en la economía como en la salud pública $(12,13,14)$.

En las muestras analizadas se observaron las deficiencias de presentación de los quesos artesanales que se expenden en el mercado del Callao. Fue notoria la falta de uniformidad, tanto de los quesos fabricados con leche de cabra como aquellos procesados con leche de vaca. Superficialmente los quesos lucían algunos rotos o desgranados; en varias muestras faltos de consistencia, con partículas de piedra superficiales y pelos, y cubiertos por hojas de plátano.

La cuajada no siempre era blanca o crema, sino de color grisáceo; con exudado de suero en algunos y textura compacta en otros, que dejaban entrever la falta de higiene y cuidado durante el proceso. 
Algunos quesos de leche de cabra, tenían manchas de color marrón, con residuos de madera, debido a que fueron ahumados.

El proceso de ahumado podría ser una manera de reducir la carga microbiana, porque en las muestras que presentaban este acabado final, los resultados de la detección de Escherichia coli enterotoxigénica fueron negativos y además se observó que el de ADN obtenido era pequeño, pero se sabe que esta operación permite que se fijen en el alimento sustancias cancerígenas provenientes c.e la madera quemada, responsable de la relación de cáncer al colon y el consumo abundante y constante de alimentos ahumados en poblaciones como la japonesa, acostumbradas al consumo abundante y constante de alimentos ahumados. De allí que no es recomendable considerar el proceso de ahumado como una medida correctiva al problema microbiológico del queso, cuando este es procesado con leches crudas contaminadas y sin respetar las normas de higiene.

Los resultados positivos de la detección de la toxina termolábil de E. coli hallados en $58.33 \%$, de las 24 muestras estudiadas, nos muestra la necesidad de implementar mejoras urgentes en la calidad sanitaria de los quesos manufacturados con leche cruda y en forma artesanal.

Si nos referimos a los productos provenientes del procesamiento con leche de cabra, estos quesos frescos tuvieron el mayor porcentaje de casos positivos $(72.72 \%)$, siendo detectada E. coli enterotoxigénica en 8 de las 11 muestras.

En los quesos manufacturados con leche de vaca se determinaron 6 casos positivos equivalentes en porcentaje al $46,16 \%$ Esto significa que a pesar de que este porcentaje es menor en $26.56 \%$ respecto a los resultados obtenidos en las muestras de leche de cabra, los hallazgos no son menos preocupantes.

Algunas referencias bibliográficas indican que en la detección de E. coli es importante la cantidad de humedad presente en el queso y que son difícilmente detectables en quesos semi suaves (17). En este estudio se ha demostrado que en quesos frescos procesados con leche cruda la presencia de E. coli productora de toxina termolábil fue hallada en porcentajes importantes.

En la detección de Escherichia coli enteropatógena productora de toxina termolábil, los cebadores empleados correspondieron al Gen labile ente- rotoxin, que nos da la certeza de que la detección positiva de la $E$. coli corresponde a la cepa productora de toxina termolábil, por usar el gen específico que posee 301 pares de bases. Este método además de confiable por su alta sensibilidad es rápido frente a otros métodos de estrategia basada en la detección del gen que demoran mucho más tiempo. A diferencia de otros métodos de análisis, la PCR es una metodología altamente sensible y rápida (demora un día en la detección del gen buscado del microorganismo específico). El gen productor de la toxina termolábil, codificado (JO 1646) en el Genbank Key, permite establecer comparaciones robustas con otros estudios.

$\mathrm{El}$ análisis estadístico de X2 indica que con un nivel de $99 \%$ de confianza se admite la Hipótesis planteada; que los resultados positivos y negativos obtenidos por la detección de $E$. coli productora de toxina termolábil mediante la PCR, no dependen de la materia prima del queso analizado, sino de la aplicación de las buenas prácticas de manufactura (BPM) y estandarización del proceso.

El desconocimiento por parte de los productores de quesos frescos de leche de cabra y de vaca, de lo importante que sería lograr la inocuidad de los productos que ellos procesan (18), frena el consumo de quesos artesanales en el mercado nacional, dejándoles con pocas posibilidades de desarrollo económico, estableciendo en el consumidor un círculo vicioso que retroalimenta efectos negativos pero reforzadores de rechazo hacia el queso artesanal.

Es pertinente recordar que un queso, independientemente del tipo de leche con el que se manufacture, no es malo porque sea procesado con leche cruda, sino cuando la leche cruda está contaminada pudiendo haber en ella gérmenes que producen ETAs (19) y proceden de animales no certificados; son leches guardadas en malas condiciones, que se han contaminado durante el ordeño o después de él con polvo, moscas, pelos, o excremento. Para plantear una solución al problema es necesario recordar que debemos procesar los quesos inmediatamente después del ordeño aprovechando la esterilidad natural de la leche (18), las buenas prácticas de manufactura, la estandarización de los procedimientos y el control de los peligros; lo cual nos permitirán mantener el control del proceso y garantizar la inocuidad de los quesos artesanales. 


\section{REFERENCIAS BIBLIOGRAFICAS}

1. Mossel D, Moreno B. 1988. Microbiología de los alimentos. Zaragoza: Edit. Acribia.

2. Riverón C R, Mena VR, González MA. 2000. Morbilidad y mortalidad por enfermedades infecciosas intestinales, Cuba, 1980-1999. Rev. Cubana Pediatría. 72(2):72-80.

3. Prado V, O'Ryan ML. 1994. Acute gastroenteritis in Latin America. Infect Dis Clin North Am. 8:77106.

4. Mayoral C, Alcázar G, Baroni M, Giani. R, Ochoteco C, Salazar F. 2008. Detección de E. coli enterotoxigénica en muestras de materia fecal diarreicas. Santa Fe. Facultad de Bioquímica y Cs. Biológicas, Universidad Nacional del Litoral.

5. Reuben A. et al. 2003. Presence of E coli O157:H7, Listeria monocytogenes y Salmonella spp in food from animal origin in Costa Rica. Archivos Latinoamericanos de Nutrición. 53 (4): 389-392.

6. Core J. 2003. Ensayos nuevos y más rápidos identifican las razas de E coli. USA. Servicio de investigación Agrícola y Universidad Estatal de Pensylvania.

7. Awad-Masalmeh M, Hassan S, Khaschabi D. 2005. Genes encoding for virulence of $\mathrm{E}$. coli causing mastitis in cattle in Austria. Vienna University of Veterinary Medicine.

8. Laboratorio MAM - lab. 2005. Protocolo de investigación. Lima.

9. Veliz C. 1998. Estadistica. 3era ed. Lima: Servicios Copias Gráficas.

10. Fernández E. 2000. Microbiología e inocuidad de alimentos, Querétaro: Universidad de Querétaro.
11. Olsen S E, MacKinnon L C, Goulding J S, Bean N H, Lutsker L S. 2000. Surveillance for foodborne-diseasse outbreaks-United States, 19931997. In: CDC Surveillance Summaries, March, 17, 2000. MMWR ; 49(No SS-1). p. 1-63.

12. Mead, P.S. ET AL. 1999. Food related illness and death in the United States. Emerging Infectious diseases. 5:607-25.

13. Castro-Rosas, J. 2005. Comportamiento de E. coli enteropatógena, enteroinvasiva y enterotoxigénica en jitomate y pepino. Hidalgo, México. Universidad Autónoma del Estado de Hidalgo.

14. Castro-Rosas J. 2005. Frecuencia y concentración de coliformes termotolerantes, $\mathrm{E}$ coli $\mathrm{y}$ grupos patógenos de E. coli en ensaladas de verduras crudas listas para su consumo obtenido en restaurantes. Hidalgo Universidad Autónoma del Estado de Hidalgo.

15. Delgado C. 2002. El requesón. Investigación e innovación tecnológica. Valladolid.

16. Asociación Peruana de Consumidores (ASPEC). 2005. En: Semana de la Escuela Profesional de Ingeniería de Alimentos. Lima. EPIA: UNAC.

17. Center for food safety and applied nutrition. 2006. Enterotoxigenic Escherichia coli. USA. USF \&DA.

18. Puga C. et al. 2005. Efecto de la refrigeración y el tiempo de almacenaje sobre la microflora natural y patógena del queso suave de leche de cabra. México: UNAM.

19. Servicio de Salud Metropolitano del Ambiente (SESMA). 2005. Consumo seguro de carnes. Servicio de salud ambiental, Chile, Región Metropolitana. 